\title{
editorial
}

\section{Einstein's grandchildren}

L ast October, the incoming German government proclaimed, in the first paragraph of its coalition agreement, its determination to "lead Germany to first place in the world in education, science and research."

Until 1933, Germany was a world leader in science. The exodus which followed, mainly to the English-speaking countries but as far afield as Turkey and Argentina, enormously enriched academia in the rest of the world. It also led to a catastrophic loss of scientific expertise in Germany itself, which might have contributed to its military defeat. In a famous exchange, in the aftermath of the 1933 purge, Hitler's education minister Bernhard Rust asked David Hilbert, one of Germany's most celebrated mathematicians, how his department in Göttingen was faring. Hilbert is reported to have responded curtly: "It no longer exists."

Although only a crude measure of national success, German scientists won the Nobel Prize on average once per year before World War II. In the seven decades since, a German-based scientist has had a share in the prize less than one-third as often. During the same period, US institutions can boast an average of two Nobel Laureates per year. Not all of them were immigrants fleeing Nazi persecution, but their arrival was a major factor in propelling their institutions to the top of the international league table, where they have remained ever since. An enlightened funding policy sustained by post-war American wealth was obviously another significant factor.

The decision to locate EMBL's main campus on German soil, taken as far back as 1974, was a bold vote of confidence in the resurrection of science in Germany. Unfortunately, and despite EMBL's success, science has not been the top priority of federal governments since that time. In fact, one could even argue that the multinational funding model for laboratories like EMBL has lessened the pressure on Germany to invest nationally in top-level research. True, the Max Planck Institutes remain an island of scientific excellence, though the situation in the universities, until recently stuck in the mentality of 1968 , is less rosy.

Much work remains to be done if the recently elected German government is to achieve its goal. However, the parlous state of US public finances and the success of American science in recent decades provide an important opportunity for Germany-and Europe as a whole-to pick up the challenge. While America has borrowed massively to finance its wars, European and Asian governments have invested increasingly in high-technology and in promoting trade. This creates a situation where, despite the much vaunted promises of the Obama administration to pump resources into innovation and science, a huge number of excellent American researchers are now seriously hurting from a continuing funding famine.

What will it take to attract Einstein's grandchildren to return? The first thing is to focus on relatively young scientists, at a time in their career when mobility is normal. But this is not enough, as attested by the limited impact, thus far, of the European Research Council's Starting Grants scheme in attracting good applicants from other continents. There has to be a well-grounded perception that this leads to an attractive career. Five years of good funding for an original research project must be followed through.

To make Europe attractive, academic salaries need to be raised to the best international standards. Those in Germany, even at entry level, are less than half of those in the USA, once adjusted for purchasing power. The potential for salary progression during an academic career is also astonishingly low, around $40 \%$. In the USA or even China, academics can expect their salary to double or in some cases treble as they reach the most senior levels. The argument that salaries must reflect 'local norms' ignores the reality that scientists are in a global marketplace.

The emotive issue of tenure also needs fresh thinking. Whereas it has all but been abolished in most European countries in favour of a more competitive system based on rolling appointments, it remains the norm in North America. The cut-throat competition for grants is sufficient to ensure research productivity, although the old cliché that the bulk of teaching is done by failed scientists is sadly true. We need a system that provides job security but also builds in substantial financial incentives for excellence in both research and teaching. At least in elite institutions, the two activities need to be much more integrated: teaching has to be better resourced, with far smaller classes, stringent student selection and time-limited degree programmes. Germany has ample opportunity there to steal a march on other European countries whose university systems are in even worse shape.

Increased resourcing is not a panacea: structural reforms are also needed. The great strength of the US academic model is autonomy. Instead of being the obedient disciples of senior mentors, associate and assistant professors in North American universities are free to choose their own research area and methodology, usually building on their personal portfolio of postdoctoral achievements, and encouraged by a non-prescriptive research grants system.

The wall of bureaucracy that increasingly separates scientists from their real work needs also to be dismantled. Basic scientists should not be expected to devote their time to the technicalities of IPR protection or developing spin-off companies to exploit their findings. Future prosperity is better served if these activities are handled by experts and properly resourced in their own right.

The German government will be judged by results. Politicians often try to find someone else to blame if they fail, but this is not an option for scientists seeking renewal of their grant. As a physicist, Dr Merkel should be well aware of this.

\section{Howy Jacobs}

EMBO reports (2010) 11, 239. doi:10.1038/embor.2010.38 